\title{
DETECTION OF TOXIC EFFECTS OF CLOSTRIDIAL CRUDE TOXIN IN EXPERIMENTAL RATS
}

\author{
M. S. Miah, M. Asaduzzaman, A. Siddika, N. Popy, M. A. Sufian and \\ M. M. Hossain* \\ Department of Pathology, Bangladesh Agricultural University \\ Mymensingh-2202, Bangladesh
}

\begin{abstract}
The present study was conducted for the detection of toxic effects of clostridial crude toxin in experimental rats. The crude toxin of Clostridium perfringens was prepared and the rats were injected intraperitoneally (IP) $0.5 \mathrm{ml}, 1.0 \mathrm{ml}$ and 2.0 $\mathrm{ml}$ of crude toxin. The rats were observed for $24 \mathrm{hrs}$. The crude toxin inoculated rats showed the dose dependent clinical signs; depression, rough hair coat, respiratory distress, diarrhea and rapid heart beats, whereas PBS inoculated rats did not show any clinical sings. Necropsy changes were variable however, highly dilated and distended whole intestine with blood stained semifluid contents and gas along with congestion in all the affected rats were found dose dependently. Liver, lung and kidney were congested, hemorrhagic and swollen. More or less hydrothorax was seen during the postmortem of all affected rats. The peritoneal fat was frequently congested in all affected rats.Histopathological changes in intestine $(0.5 \mathrm{ml}$ inoculated rats $)$ involved congestion, slightly swollen goblet cells and hemorrhages. The most severe lesions comprised of profuse hemorrhages in the mucosa and submucosa with complete necrosis, desquamation and intense leukocytic infiltration in $2 \mathrm{ml}$ inoculated rats. Affected liver ( $1 \mathrm{ml}$ inoculated rats) exhibited engorgement of central veins, sinusoidal spaces with blood and fatty change. The hepatocytes revealed swelling, granulation and vacuolation of cell cytoplasm, extensive hemorrhage and congestion were seen in $2 \mathrm{ml}$ toxin inoculated rats. Congestion and sometimes extravasation were observed in the subepicardial region of heart. The myocardium revealed mild degenerative changes in the form of granularity of myocardial fiber. In lungs there was congestion, hemorrhage and leukocytes infiltration in the interstitial spaces around the bronchioles in both 1 and $2 \mathrm{ml}$ toxin inoculated rats. Affected kidneys of different doses of crude toxin showed hemorrhage, congestion and inflammatory cells dose dependently. From the above findings, it may be concluded that clostridial crude toxin induced clinical signs, gross and histopathological lesions dose dependently in experimental rats.
\end{abstract}

Key Words: Crude toxin, Toxic effect, Rat, Gross lesions, Histopathological lesions

\footnotetext{
* Corresponding author. E-mail: mmhossain04@yahoo.com.au
} 


\section{INTRODUCTION}

The Gram-positive pathogen Clostridium perfringens is a major cause of human and veterinary enteric disease largely because this bacterium can produce several toxins when present inside the gastrointestinal tract (Smedley et al., 2005). It is considered to be most widely occurring pathogenic bacterium (Hatheway, 1990). The organism produces several toxins of which beta and epsilon are the most lethal types (El-Idrissi and Ward, 1992). Pathological changes produced by whole growing culture of Clostridium perfringens in guineapigs has been reported (Tripathi, 1990). Several authors (Lawrence and Walker, 1976; Tripathi, 1990) failed to produce diseases in rats by filtrate of Clostridium perfringens orally which might be due to neutralization of toxin by pancreatic juice in duodenum. The role of parenteral administration of causal bacterial toxin is needed to be elucidated. Therefore an attempt was made to observe the pathological findings in rats with IP administration of Clostridium perfringens crude toxins.

\section{MATERIALS AND METHODS}

\section{Clostridium perfringens bacteria}

The bacteria Clostridium perfringens was obtained from Department of Pathology, Faculty of Veterinary Science, Bangladesh Agricultural University, Mymensingh, Bangladesh.

\section{Culture of bacteria and recharacterization}

The obtained bacteria Clostridium perfringens was recharacterized by culture in nutrient broth, stab culture, carbohydrate fermentation test, methyl red (MR) test, VogesProskauer (V-P) test, indole test, dulcitol fermentation test, catalase test, blood agar for hemolytic activity test, egg yolk agar for lecithinase test, TSI agar slant reaction (Rahman et al., 1999; Eyre, 2009).

\section{Preparation of crude toxin of Clostridium perfringens}

A colony from the subcultures of Clostridium perfringens, grown on stab culture at $37^{\circ} \mathrm{C}$ for two days was transferred to nutrient broth and maintained anaerobic condition in candle jar at $37^{\circ} \mathrm{C}$. After one week the growing culture was placed in a rotary shaker at room temperature for eight hours. About $20 \mathrm{ml}$ of cultured broth was taken in a sterile Falcon tube and centrifuged at $3000 \mathrm{rpm}$ for 30 minutes and about $15 \mathrm{ml}$ of supernatant was collected. The supernatant was then passed through a filter paper and the filtrate was treated with $1 \mathrm{ml}$ of 1 mole ammonium sulphate at room temperature and kept it for 24 hours at $4^{\circ} \mathrm{C}$. After precipitation the supernatant was decanted. The precipitated mass of crude toxin was washed by centrifugation with acetone for three times at $15000 \mathrm{rpm}$ for 15 minutes. Finally, the crude toxin was diluted with $15 \mathrm{ml}$ of PBS (pH 7.4) and stored at $4^{\circ} \mathrm{C}$ (Tripathi, 1990; El-Idrissi and Ward, 1992 and Smedley et al., 2005). 


\section{Experimental design}

The present study was conducted for the detection of toxic effects of clostridial crude toxin in experimental rats. Apparently healthy 18 rats (ICDDR'B, Dhaka), 3 months age, body weight 200 to $250 \mathrm{gm}$ each was used for this observation. All these rats were maintained group wise in seperate cages with balanced laboratory ration, clean drinking water ad libitum in a well-lighted and ventilated room. The rats were divided into experimental and control groups. The experimental rats were injected 0.5, 1.0 and $2.0 \mathrm{ml}$ of crude Clostridium perfringens toxins IP while control rats received $0.5 \mathrm{ml}, 1 \mathrm{ml}$ and $2 \mathrm{ml}$ of PBS respectively (Rahman et al., 1999). Each group consisted of 3 rats.

\section{Grading of clinical signs}

The clinical signs was graded as,+++ and +++ . The + was characterized by rough hair coat and mild respiratory distress. The ++ was categorized by depression, rough hair coat, respiratory distress and diarrhea. The +++ was characterized by depression, rough hair coat, respiratory distress, diarrhea and rapid heart beat by visual inspection.

\section{Histopathology}

For histopathology, the different tissues (intestine, liver, heart etc.) from experimental and control rats were preserved in 10\% neutral buffered formalin. The processing of tissues was performed following routine procedure (Luna, 1968).

\section{Histopathological studies and photomicrography}

Histopathological examinations of the tissues were studied and photomicrography was taken at the Department of Pathology, BAU, Mymensingh using compound microscope and photomicrographic camera (Olympus PM-C 35 Model).

\section{RESULTS AND DISCUSSION}

The clinical signs showed by rats after injecting toxins at $0.5,1.0$ and $2.0 \mathrm{ml}$ were categorized as,+++ and +++ , respectively. The rats expressed clinical signs dose dependently. All rats of toxin inoculated groups became dull and depressed after 5-6 hrs of administration of crude toxin. Rats showed characteristic signs of subnormal temperature, rough hair coat, respiratory distress and feeble heart beat. The control rats did not exhibit any sign of illness. The results of gross and histopathology of rats are presented in Table 1.

Necropsy changes were highly dilated and distended intestine with blood stained semifluid contents and gas along with congestion in all the affected rats dose dependently. Moderate degree of congestion was observed in the duodenum and proximal part of the jejunum. Rest of the jejunum and entire ileal walls were severely congested and hemorrhagic. The severely congested and hemorrhagic part of intestine was also distended with gases. The severity of congestion progressively increased towards the ileum. Liver, lung and kidney were congested, hemorrhagic and swollen. 
More or less hydrothorax was seen during the postmortem of all affected rats. The peritoneal fat was congested in all affected rats. However, all lesions were not found in all organs of rats (Figs. 1-8, Table 2).

Table 1. Shows clinical sign of rats

\begin{tabular}{l|c|c|c|c}
\hline Group & Type of inoculum & $\begin{array}{c}\text { Amount injected } \\
(\mathrm{ml} / \mathrm{rat})\end{array}$ & $\begin{array}{c}\text { Clinical signs } \\
\text { (Toxin inoculated) }\end{array}$ & $\begin{array}{c}\text { Clinical signs } \\
\text { (PBS inoculated) }\end{array}$ \\
\hline A & CRUDE TOXIN & 0.5 & + & - \\
B & $\&$ & 1.0 & ++ & - \\
C & PBS & 2.0 & +++ & - \\
\hline
\end{tabular}

- = Absence, $+=$ Rough hair coat and mild respiratory distress, $++=$ Depression, rough hair coat, respiratory distress and diarrhea, $+++=$ Depression, rough hair coat, respiratory distress, rapid heart beat and diarrhea

Histopathological changes in intestine $(0.5 \mathrm{ml}$ inoculated rats) involved congestion, slightly swollen goblet cells and hemorrhages. The most severe lesions comprised of profuse hemorrhages in the mucosa and submucosa with complete necrosis, desquamation and intense leukocytic infiltration in $2 \mathrm{ml}$ inoculated rats. Affected liver ( $1 \mathrm{ml}$ inoculated rats) exhibited engorgement of central veins, sinusoidal spaces with blood and fatty change of hepatocytes. The hepatocytes revealed swelling, granulation and vacuolation of cell cytoplasm, extensive hemorrhage and congestion were seen in 2 $\mathrm{ml}$ toxin inoculated rats. Congestion and sometimes extravasations were observed in the subepicardial region of heart. The myocardium revealed mild degenerative changes in the form of granularity of myocardial fiber. In lungs there was congestion, hemorrhage and leukocytes infiltration in the interstitial spaces around the bronchioles in both 1 and 2 $\mathrm{ml}$ toxin inoculated rats. Affected kidney of different doses of crude toxin showed hemorrhage, congestion and inflammatory cells (Figs. 9-16, Table 3).

Table 2. Shows gross lesions of rats

\begin{tabular}{c|c|c|c|c|c|c|c}
\hline Group & $\begin{array}{c}\text { Type of } \\
\text { inoculum }\end{array}$ & $\begin{array}{c}\text { Amount } \\
\text { injected } \\
\end{array}$ & & \multicolumn{3}{|c|}{ Gross lesions (Toxin inoculated) } & $\begin{array}{c}\text { Gross lesions } \\
\text { (PBS inoculated) }\end{array}$ \\
\cline { 4 - 8 } & & & Intestine & Liver & Lungs & $\begin{array}{c}\text { Peritoneal } \\
\text { fat }\end{array}$ & $\begin{array}{c}\text { intestine, liver, lung } \\
\text { and peritoneal fat }\end{array}$ \\
\hline A & CRUDE & 0.5 & + & - & - & + & - \\
B & TOXIN \& & 1.0 & ++ & ++ & ++ & ++ & - \\
C & PBS & 2.0 & +++ & +++ & +++ & +++ & - \\
\hline
\end{tabular}

- = Absence,$+=$ Slight congestion in intestine; congestion in peritoneal fat,$++=$ Congestion and petechial hemorrhage in intestine; Hemorrhage in liver; Hydrothorax, congestion in lungs and congestion in peritoneal fat, $+++=$ Fluid filled lumen, severe hemorrhage in intestine; Hemorrhage in liver; Hydrothorax and fluid filled right lung and congestion and hemorrhage in peritoneal fat. 


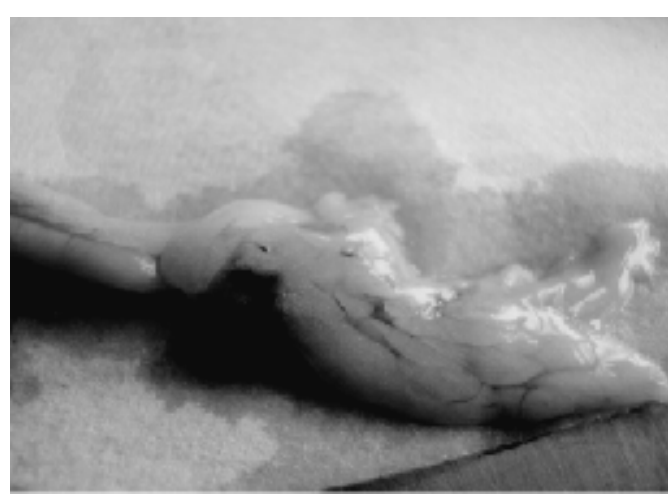

Fig. 1. Peritoneal fat of rat. A total of $0.5 \mathrm{ml}$ crude toxin inoculated IP and examined $24 \mathrm{hrs}$ PI (post inoculation) shows congestion

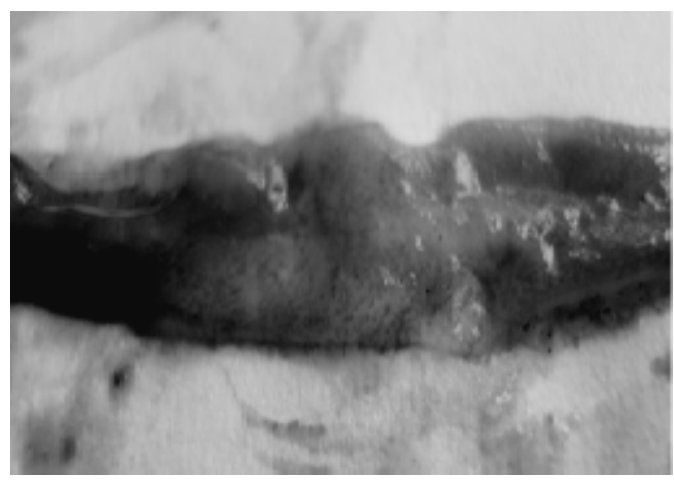

Fig. 3. Duodenum of rat. A total of $1 \mathrm{ml}$ crude toxin inoculated IP and examined $24 \mathrm{hrs}$ PI shows congestion and petechial hemorrhage

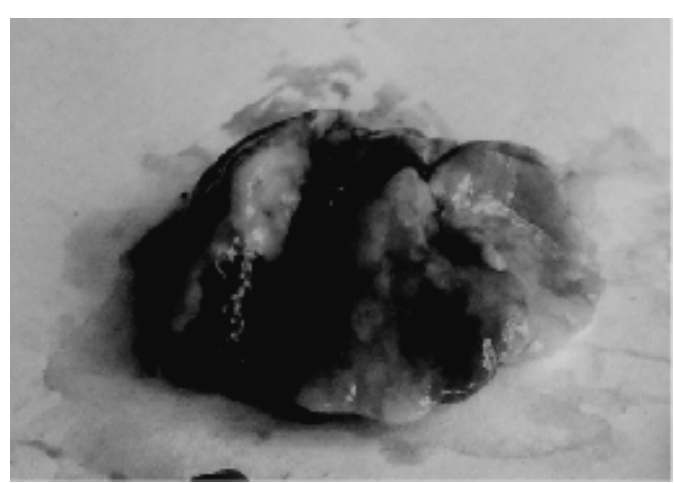

Fig. 5. Lung of rat. A total of $1 \mathrm{ml}$ crude toxin inoculated IP and examined $24 \mathrm{hrs}$ PI shows slight congestion and fluid filled lung

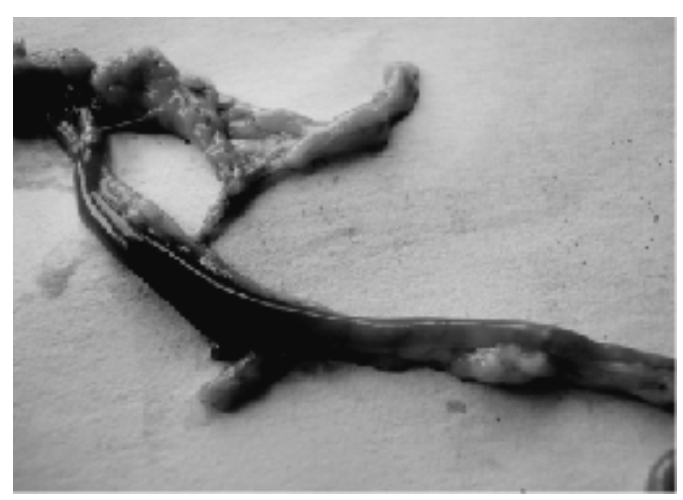

Fig. 2. Intestine of rat. A total of $0.5 \mathrm{ml}$ crude toxin inoculated IP and examined $24 \mathrm{hrs}$ PI shows slight congestion and intestinal lumen filled with fluid

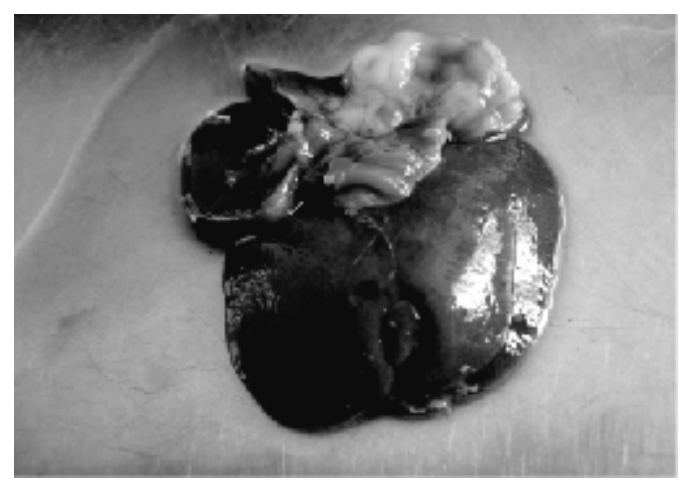

Fig. 4. Liver of rat. A total of $1 \mathrm{ml}$ crude toxin inoculated IP and examined $24 \mathrm{hrs}$ PI shows hemorrhage

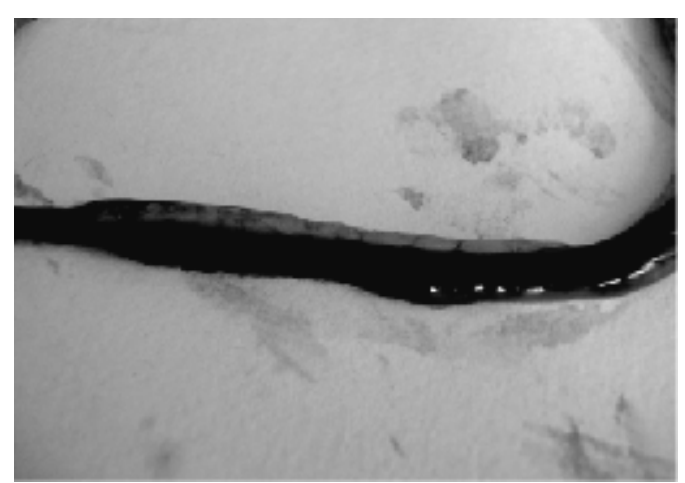

Fig. 6. Duodenum of rat. A total of $2 \mathrm{ml}$ crude toxin inoculated IP and examined $24 \mathrm{hrs}$ PI shows fluid filled lumen and severe hemorrhage in duodenum 


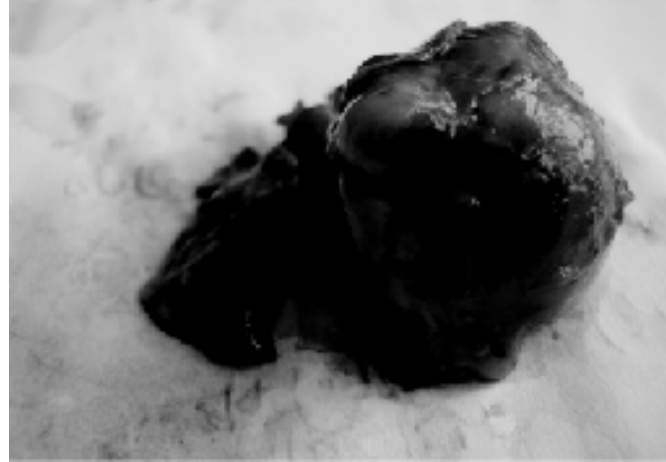

Fig. 7. Lung of rat. A total of $2 \mathrm{ml}$ crude toxin inoculated IP and examined $24 \mathrm{hrs}$ PI shows hydrothorax and fluid filled right lung

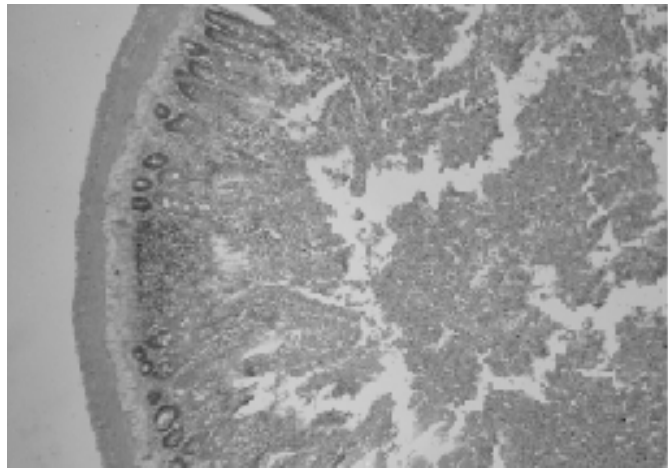

Fig. 9. Intestine of rat. A total of $0.5 \mathrm{ml}$ crude toxin inoculated IP and shows slightly swollen goblet cells and presence of inflammatory leukocytes and exudates in the lumen (H\&E stain, x82.5)

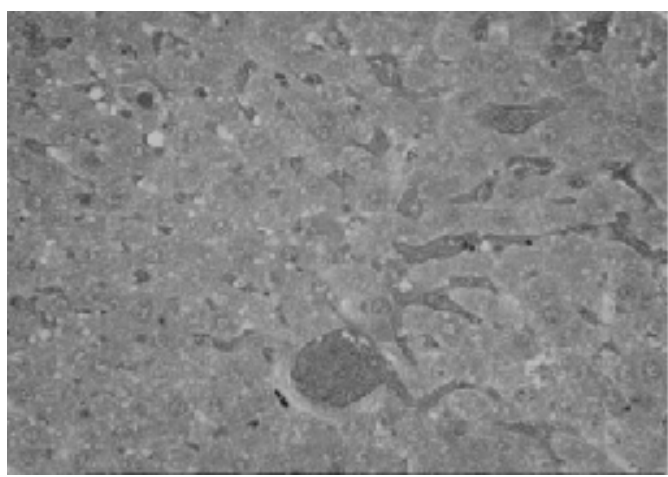

Fig. 11. Liver of rat. A total of $1 \mathrm{ml}$ crude toxin inoculated IP and affected liver shows fatty change and congestion in sinusoids and central vein (H\&E stain, x330)

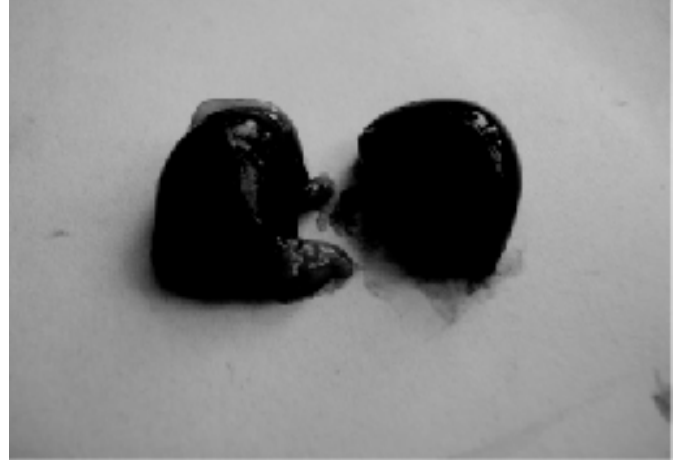

Fig. 8. Kidneys of rat. A total of $2 \mathrm{ml}$ crude toxin inoculated IP and examined 24 hrs PI shows swollen and congested kidneys

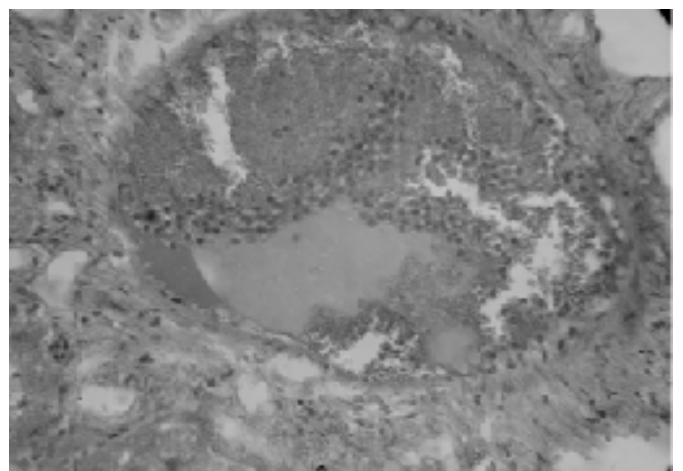

Fig. 10. Kidney of rat. A total of $0.5 \mathrm{ml}$ crude toxin inoculated IP and affected kidney shows congestion (H\&E stain, $\times 330$ )

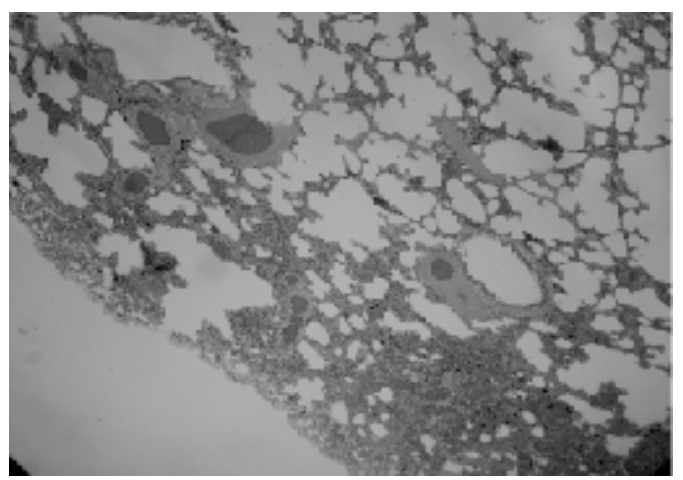

Fig. 12. Lung of rat. A total of $1 \mathrm{ml}$ crude toxin inoculated IP and affected lung shows congestion and hemorrhage in interalveolar septae and rupture of some alveoli. (H\&E, x82.5) 


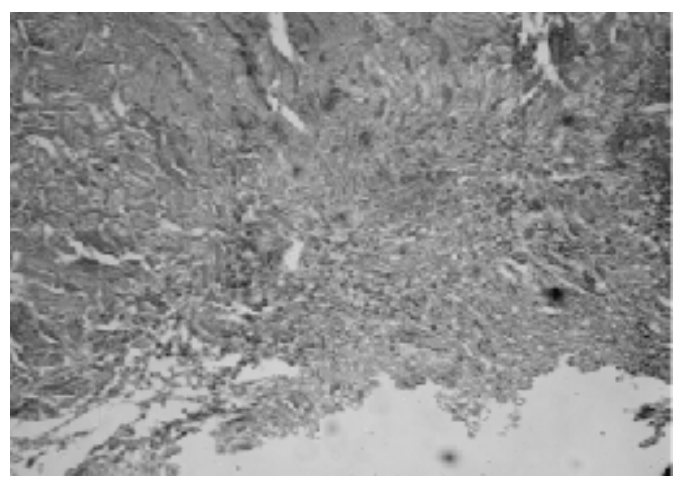

Fig. 13. Kidney of rat. A total of $1 \mathrm{ml}$ crude toxin inoculated IP and affected kidney shows congestion and hemorrhage (H\&E, x82.5)

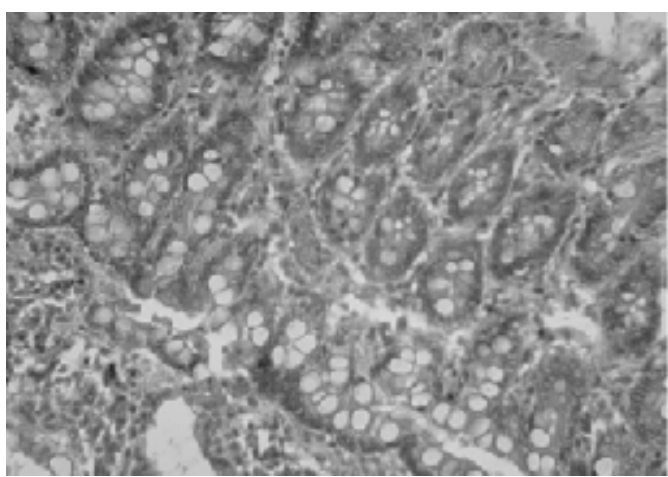

Fig. 15. Intestine of rat. A total of $2 \mathrm{ml}$ crude toxin inoculated IP and affected intestine shows swollen goblet cells and intense leukocytic infiltration in mucosa, submucosa and lumen (H\&E, x330)

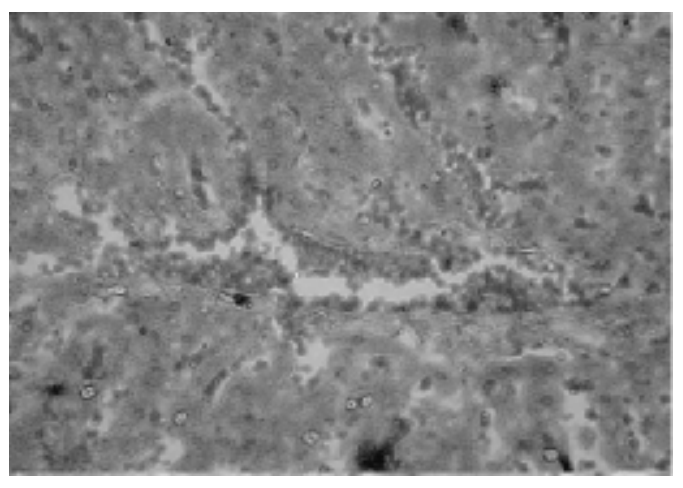

Fig. 14. Liver of rat. A total of $2 \mathrm{ml}$ crude toxin inoculated IP and affected liver shows profuse hemorrhage, congestion, fatty change and congestion in sinusoids and central vein $(\mathrm{H} \& \mathrm{E}, \mathrm{x} 330)$

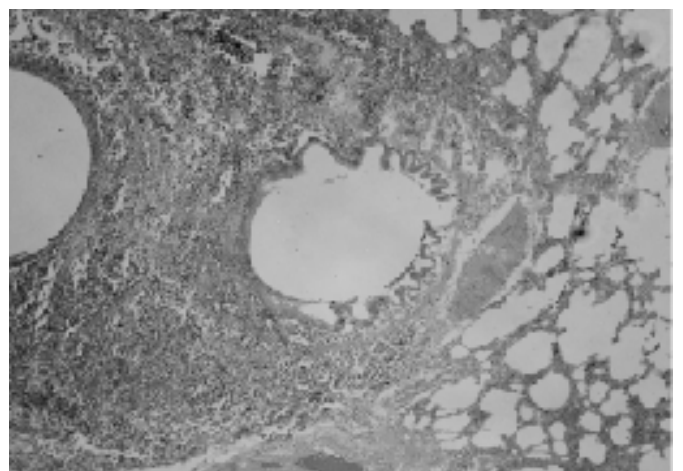

Fig. 16. Lung of rat. A total of $2 \mathrm{ml}$ crude toxin inoculated IP and affected lung shows congestion, hemorrhage and leukocytes infiltration in the interstitial spaces around the bronchioles (H\&E, x82.5)

In the present study, crude toxin prepared from Clostridium perfringens for the determination of toxicity that was reported by several scientists ((Tripathi, 1990; El-Idrissi and Ward, 1992 and Smedley et al., 2005). Several authors (Lawrence and Walker, 1976) failed to produce diseases in rats by filtrate of Clostridium perfringens orally, which might be due to neutralization of toxin by pancreatic juice in duodenum. In this study, crude toxin inoculated rats showed the dose dependent clinical signs of depression, rough hair coat, respiratory distress, diarrhea, feeble heart beats which were supported by the findings of other authors (Hatheway, 1990; Tripathi, 1990, El- Idrissi and Ward, 1992; Rahman et al., 1999 and Smedley et al., 2005). In the present experiment, the results of toxicity test with prepared crude toxin in rats were in agreement with the earlier results of other investigators (Lawrence and Walker, 1976; Tripathi, 1990; Hatheway, 1990; ElIdrissi and Ward, 1992; Rahman et al., 1999 and Smedley et al., 2005). 
Table 3. Shows histopathological lesions

\begin{tabular}{|c|c|c|c|c|c|c|c|}
\hline \multirow[t]{2}{*}{ Group } & \multirow[t]{2}{*}{$\begin{array}{l}\text { Type of } \\
\text { inoculum }\end{array}$} & \multirow{2}{*}{$\begin{array}{l}\text { Amount } \\
\text { injected } \\
(\mathrm{ml} / \mathrm{rat})\end{array}$} & \multicolumn{4}{|c|}{$\begin{array}{l}\text { Histopathological lesions } \\
\text { (Toxin inoculated) }\end{array}$} & \multirow{2}{*}{$\begin{array}{c}\text { Histopathological lesions } \\
\text { (PBS inoculated) }\end{array}$} \\
\hline & & & Intestine & Liver & Lungs & Heart & \\
\hline A & CRUDE & 0.5 & + & - & - & + & - \\
\hline B & $\begin{array}{l}\text { TOXIN } \\
\&\end{array}$ & 1.0 & ++ & ++ & + & ++ & - \\
\hline C & PBS & 2.0 & +++ & +++ & +++ & +++ & - \\
\hline
\end{tabular}

- = Absence, $+=$ Slight congestion in intestine and congestion in heart, $++=$ Congestion and profuse hemorrhage in mucosa in intestine; Engorgement of central veins and sinusoidal spaces with blood in liver; Congestion and hemorrhage in lungs and congestion and sometimes extravasations were observed in the subepicardial region of heart, $+++=$ Hemorrhage, necrosis, desquamation and intense leukocytic infiltration in intestine; Hepatocytes revealed swelling, granulation and vacuolation of cell cytoplasm in liver; congestion, hemorrhage and leukocytes infiltration in the interstitial spaces around the bronchioles and congestion and degenerative changes in the form of granularity of myocardial fiber

\section{CONCLUSIONS}

The parenteral administration of crude toxin of Clostridium perfringens induced clinical signs, gross and histopathological lesions dose dependently in experimental rats.

\section{REFERENCES}

El-Idrissi, A. H. and Ward, G. E. 1992. Evaluation of enzyme linked. immunosorbent assay for diagnosis of Clostridium perfringens enterotoxemias. Vet. Microbiol., 31: 389-396.

Eyre J. W. H. 2009. The Elements of Bacteriological Technique, A Laboratory Guide for Medical, Dental, and Technical Students. $2^{\text {nd }}$ edn., Press of W. B. Saunders Company Philadelphia.

Hatheway, C. L. 1990. Toxigenic clostridia. . Clin. Microbiol. Rev., 3(1): 66-98.

Luna, L. G. 1968. Manual of Histologic Staining Methods of the Armed Forces Institute of Pathology. $3^{\text {rd }}$ edn. McGraw Hill Book Co., New York, USA.

Lawrence, G. W. and Walker, P. W. 1976. Experimentally induced necrotic enteritis in chickens. Avian Dis., 31: 904-906.

Rahman, M. S., Rahman, M. M. and Khan, M. A. H. N. A. 1999. Clinicopathological observations of Clostridium perfringens toxins in experimental guineapigs. Thesis submitted to Department of Veterinary Medicine, Faculty of Veterinary Science, Bangladesh Agricultural University, Mymensigh-2202, Bangladesh

Smedley, J. G., Fisher D. J., Sayeed, S. Chakrabarti, G. and McClane, B. A. 2005. The enteric toxins of Clostridium perfringens. Rev. Physiol. Biochem. Pharmacol., 152: 183-204.

Tripathi, B. N., 1990. Studies on pathological changes induced by Clostridium perfringens Type C in guineapigs and piglets. Ph. D. Thesis, Indian Veterinary Research Institute, Izatnagar, UP, India. 